\title{
Revista Pediatría de Atención Primaria: en camino hacia el acceso abierto
}

\author{
JC. Buñuel Álvarez \\ Pediatra de Atención Primaria. Àrea Bàsica de Salut Girona-4 (Institut Català de la Salut). Girona. España.
}

Rev Pediatr Aten Primaria. 2009; I :203-6

José Cristóbal Buñuel Álvarez, jcbunuel@gmail.com

Se conoce como acceso abierto (AA) a un movimiento surgido oficialmente en 2001 con la declaración de Budapest' ${ }^{1}$, y terminado de concretar con las declaraciones de Bethesda y Berlín ${ }^{2,3}$. Dicho movimiento propone un nuevo paradigma en la relación autor-editor, centrado básicamente en el acceso libre y sin restricciones de ningún tipo al contenido de los artículos originales de las revistas y en la conservación, por parte de los autores, de todos o parte de los derechos de copyright de su obra.

Dentro del campo de las ciencias biomédicas, la accesibilidad completa al contenido de las principales revistas científicas ha de ser entendido como un derecho fundamental. Las barreras actualmente existentes en muchas revistas para acceder a sus contenidos pueden ser fuente de desigualdad y dar origen, desde el punto de vista del conocimiento científico, a profesionales de dos velocidades: los que pueden acceder al mismo mediante el pago de la suscripción correspondiente por su parte o por la institución sanitaria a la que pertenecen y los que no pueden permitirse este pago.

Como acertadamente señala B. San José $^{4}$ en su artículo publicado en este número de la Revista Pediatría de Atención Primaria, y en consonancia con otros autores ${ }^{5}$ se da el caso, además, de que muchas instituciones sanitarias se ven obligadas a pagar dos veces por la investigación que generan: una vez, por los costes derivados de la investigación que financian y otra vez por la suscripción a la revista en la que dicha investigación se publicará.

El movimiento AA establece dos grandes vías para adherirse al mismo: la verde y la dorada ${ }^{4,5}$. Dichas vías no son excluyentes entre sí, ya que una editorial puede tomar la decisión de declarar a 
una o varias de sus revistas como de AA (vía dorada) y, simultáneamente, permitir el autoarchivo de sus contenidos en repositorios institucionales (vía verde). El autoarchivo en repositorios no implica en modo alguno una pérdida de identidad de la revista, sino que aumenta la accesibilidad a sus contenidos ya que permite el acceso a sus artículos a través de varias puertas de acceso: el sitio web propio de la editorial y el/los repositorio/s en los que sus contenidos están alojados.

\section{La Revista Pediatría de Atención}

Primaria ante el movimiento de acceso abierto

La Revista Pediatría de Atención Primaria (RPAP) ha dado, en los últimos años, diversos e importantes pasos en la dirección propuesta por el movimiento AA:

1. Puede accederse, de forma gratuita $y$ sin restricciones, a todos los artículos publicados en la revista a través de la página web de la misma (www.pap.es).

2. Los contenidos de RPAP están también accesibles en repositorios institucionales como por ejemplo Dialnet, de la Universidad de La Rioja (http://dialnet.uni rioja.es).

Recientemente, la RPAP ha sido admitida en la plataforma SciELO ${ }^{6}$, el princi- pal portal latinoamericano de revistas que permiten el acceso sin restricciones a su contenido.

Los pasos descritos son decisivos para aumentar la visibilidad de la revista y para que sus contenidos sean conocidos y difundidos entre todos los profesionales sanitarios interesados en la salud infantojuvenil.

Queda por redefinir la relación autoreditor. La RPAP, como otras revistas, ha iniciado un camino en la dirección del movimiento AA. Este movimiento propugna que los autores de los artículos conserven el copyright de su obra. Entre la cesión total de los derechos de copyright a la editorial propietaria de la revista y la conservación íntegra de los mismos por parte de los autores de los artículos, existe una amplia gama de posibilidades que pueden satisfacer a ambas partes. Con este fin surgieron las licencias Creative Commons ${ }^{7}$, para regular la relación autor-editor; esta es una organización sin fines de lucro que ha desarrollado una serie de estándares y referencias ("licencias de uso") que explicitan las condiciones elegidas por el autor o editor, bajo las cuales los usuarios pueden distribuir $y$ utilizar su obra o contenidos. Dichas licencias, aún escasamente difundidas en nuestro medio, han sido ya adoptadas por algunas revistas pediátricas. Por 
ejemplo, la revista Boletín de Pediatría, incluida en el DOAJ (Directory of Open Access Journals, el portal más importante de revistas de acceso abierto del mundo), ha optado por una licencia "Reconocimiento-No comercial 2.5 España" que establece las condiciones de la relación autor-editor-usuarios. La versión íntegra de dicha licencia puede consultarse en http://creativecommons.org/licenses/by -nc/2.5/es/legalcode.es. La RPAP redefinirá a corto plazo la relación autor-editor-usuarios por medio de una licencia Creative Commons para pasar del actual "todos los derechos reservados" a "algunos derechos reservados".

Los autores, a la hora de tomar la decisión de publicar los resultados de su trabajo en una revista científica, deben conocer cuál es la política de la misma respecto a los artículos que publica y a los derechos de los autores. Esos datos deberían constar claramente especificados en el apartado de normas de publicación, pero lamentablemente esto no siempre sucede así, al ser esta información incompleta en algunos casos o estar ausente en otros 5 . Para corregir estas carencias, en España ha surgido el proyecto DULCINEA $^{8}$. Como consta en su web, DULCINEA, por su analogía con el proyecto ROMEO-Sherpa (www.sherpa.ac. uk/about.html), es un proyecto cuyo ob- jetivo es conocer las políticas editoriales de las revistas españolas respecto al acceso a sus archivos, los derechos de copyright sobre los mismos y cómo estos pueden afectar a su posterior autoarchivo en repositorios institucionales o temáticos. La base de datos de DULCINEA es de enorme interés para autores y editores, ya que permite al autor escoger el tipo de publicación que, por su política editorial, más se ajusta a sus necesidades. Para los editores resulta de utilidad al poder comparar su política editorial con las de otros colegas o competidores. Dentro del ámbito pediátrico español, son tres las revistas que hacen constar explícitamente su política editorial en la actualidad: Evidencias en Pediatría, Boletín de Pediatría y Anales de Pediatría. A corto plazo, la política editorial de la RPAP podrá ser consultada también a través de esta base de datos.

La adhesión a los postulados del movimiento de AA ha de ser considerada como un proceso paulatino. Muchas revistas han nacido ya desde dentro de este movimiento (por ejemplo, las del portal BioMed Central, o Plos Medicine). Otras, la mayoría, han iniciado un camino desde un formato tradicional (que podríamos llamar closed access) hacia el AA. En un paso intermedio se encuentra actualmente la RPAP, aunque con una clara voca- 
ción de ser de AA a medio plazo. Desde el comité editorial de la RPAP esperamos y deseamos que todos estos pasos sean del interés de sus lectores y que compartir los derechos con los autores, el libre acceso a los contenidos de los artículos y la publicación en repositorios (garantizando así una amplia difusión y visibilidad de los mismos), sirvan de estímulo a los potenciales autores y usuarios.

\section{Bibliografía}

1. Iniciativa de Budapest para el Acceso Abierto [consultado el 18/05/2009]. Disponible en www. soros.org/openaccess/esp/index.shtml

2. Declaración de Bethesda sobre Publicación de Acceso Abierto [consultado el 18/05/2009]. Disponible en http://ictlogy.net/articles/bethesda_es. html

3. Berlin Declaration on Open Access to Knowledge in the Sciences and Humanities [consultado el 18/05/2009]. Disponible en http://oa.mpg.de/ openaccess-berlin/berlindeclaration.html
4. San José Montano B. Acceso abierto (open access), un modelo necesario de comunicación científica. Rev Pediatr Aten Primaria. 2009;11:299311.

5. Abad F, González A, Martínez C. Acceso abierto y revistas médicas españolas. Med Clin (Barc). 2006;127(12):356-64.

6. SciELO [consultado el 18/05/2009]. Disponible en http://scielo.isciii.es/scielo.php

7. Creative Commons [consultado el 18/05/ 2009]. Disponible en http://es.creativecommons. org/

8. DULCINEA [consultado el 18/05/2009]. Disponible en www.accesoabierto.net/dulcinea/

\section{Ver también en este número}

Acceso abierto (open access), un modelo necesario de comunicación científica. B. San José Montano (página 299). 